\title{
Efficacy and Safety of Aluminum Chloride in Controlling External Hemorrhage: An Animal Model Study
}

\author{
Saeed Nouri ${ }^{1}$; Mohammad Reza Sharif ${ }^{2, *}$; Yunes Panahi ${ }^{1}$; Mostafa Ghanei ${ }^{1}$; Bardia Jamali ${ }^{1}$ \\ ${ }^{1}$ Chemical Injuries Research Center, Baqiyatallah University of Medical Sciences, Tehran, IR Iran \\ ${ }^{2}$ Trauma Research Center, Kashan University of Medical Sciences, Kashan, IR Iran \\ ${ }^{*}$ Corresponding Author: Mohammad Reza Sharif, Trauma Research Center, Kashan University of Medical Sciences, Kashan, IR Iran. Tel: +98-9123788713, Fax: +98-3615558900, E-mail: \\ mrsharifmd@yahoo.com
}

Received: May 5, 2014; Revised: January 27, 2015; Accepted: February 17, 2015

\begin{abstract}
Background: Despite all the progress in surgical science, bleeding caused by traffic accidents is still one of the challenges surgeons face in saving patients' lives. Therefore, introducing an effective method to control external bleeding is an important research priority.

Objectives: This study aimed to compare the hemostatic effect of aluminum chloride versus simple suturing in controlling external bleeding.

Materials and Methods: This experimental study was conducted in Kashan, Iran. In this study, 60 male Wistar rats were randomly allocated into six groups. An incision, two centimeters $(\mathrm{cm})$ long and half a $\mathrm{cm}$ deep, was made on each rat's shaved back skin and the hemostatic time was measured once using aluminum chloride with different concentrations $(5 \%, 10 \%, 15 \%, 25 \%$, and $50 \%)$ and then using the control method (controlling hemorrhage by simple suturing). The skin tissue was assessed for pathological changes.

Results: The hemostatic time of aluminum chloride $50 \%, 25 \%, 15 \%, 10 \%$ and $5 \%$ were $8.20 \pm 0.919,14.10 \pm 1.37,21.20 \pm 1.31,30.80 \pm 1.68$ and 42.00 \pm 4.19 seconds, respectively. Also, the mean hemostasis time in the control group (suture) was $84.00 \pm 4.05$ seconds. The hemostatic times of different concentrations of aluminum chloride were significantly less than that of the control group. There was a statistically significant difference between every two hemostatic time. The pathologic examination showed the highest frequency of low-grade inflammation based on the defined pathological grading.

Conclusions: The aluminum chloride method needs less time to control external hemorrhage compared to the control method (controlling external hemorrhage by simple suturing). Aluminum chloride is an effective agent in controlling external hemorrhage in an animal model.
\end{abstract}

Keywords: Hemorrhage; Hemostasis; Aluminum Chloride; Rats

\section{Background}

Bleeding, particularly bleeding caused by traffic accidents remains one of the main causes of traffic accident deaths. Preventing death through stopping or minimizing blood loss until advanced medical help is the main target of the healthcare team (1). Applying external pressure, suturing technique and in some cases elevating the bleeding site are the best options currently available to control external bleeding $(2,3)$. Simple suture is possible only in medical centers and by trained staff. Topical agents which act by stimulating hemostasis at the surface of skin are another way to control bleeding. Aluminum chloride is a chemical agent with acidic property and formula of $\mathrm{AlCl}_{3}$. Aluminum chloride is used as a hemostatic agent frequently used to control the local bleeding in dental surgeries (4). Moreover, it is widely used in water purify as a protein coagulant (5).

This property thereof, with regard to the significant amount of proteins in blood, makes aluminum chloride a very strong hemostatic agent. In fact, aluminum chloride exerts its hemostatic effect through a chemical reac- tion with blood proteins, and this property makes aluminum chloride a very efficient hemostatic agent. Then, it may be an effective hemostatic agent that adequately satisfies surgeons' need to control bleeding even in patients with abnormal body hemostatic system. Although the hemostatic effect of aluminum chloride has already been found, its effect in controlling external bleeding has not assessed and compared with suturing technique as a standard method.

\section{Objectives}

This study aimed to compare the hemostatic effect of aluminum chloride versus simple suturing technique in controlling external hemorrhage.

\section{Materials and Methods}

\subsection{Animals and Sampling}

This experimental study took place at Kashan University of Medical Sciences from August 2013 to December 2013. 
In this study, 60 male Wistar rats (weighting 180 - 230 g) were randomly allocated into 6 groups (simple randomization) of 10 rats each. According to the pilot study, mean hemostatic time of the six groups were 43.3, 30.6, 19.6, $15.3,9.1,84.3$ seconds, respectively and total variance was 16.9. Considering $\alpha=0.05$ and $1-\beta=0.8$, sample size was estimated at 10 in each group. One week before study, animals were kept at $21 \pm 1^{\circ} \mathrm{C}$ with a 12-hour light/dark cycle (lights on from 8:00 AM to 8:00 PM). They had free access to standard rat chaw and water ad libitum.

\subsection{Surgery}

Rats were anesthetized by intraperitoneal (ip) injection of a ketamine/xylazine mixture (ketamine $100 \mathrm{mg} / \mathrm{kg}$ and xylazine $10 \mathrm{mg} / \mathrm{kg}$ ). The $10 \%$ ketamine and $2 \%$ xylazine (Alfasan, Holland) were purchased from local supplier (Shahid-Beheshti Hospital Pharmacy, Kashan, Iran). An incision of two $\mathrm{cm}$ in length and half a $\mathrm{cm}$ in depth was made on each rat's shaved back skin by scalpels NO. 10 .

\subsection{Aluminum Chloride Administration and Mea- suring Hemostatic Time}

Aluminum chloride was purchased from Merck, (Darmstadt, Germany). Aqueous solution of aluminum chloride was prepared in five concentrations of $50 \%, 25 \%, 15 \%$, $10 \%$ and $5 \%(\mathrm{w} / \mathrm{v})$ in distilled water, each concentration to be used in one group of rats. Half a milliliter volume of solution was applied to the incision site by an insulin syringe. The times of hemostasis were measured using a chronometer. The hemostasis time was considered as the time required for complete drying of bleeding and no blood discharge from the incision site (Figure 1). The mean of the measured times in the ten rats in each group was considered as the hemostatic time for each aluminum chloride concentration. Simple suturing using nylon 3-0 was used as the standard method of hemostasis in the control group. All simple sutures were performed by one surgeon. After controlling external bleeding, each rat was treated intraperitoneally with $50 \mathrm{mg}$ keflin $(1 \mathrm{~g}$ cefalotin/10 mL, Aspen Pharmacare Australia Pty Ltd, Australia).

\subsection{Pathological Study}

Seven days after the treatment, all rats were anesthetized using IP injections of a mixture of ketamine and xylazine (ketamine $100 \mathrm{mg} / \mathrm{kg}$ and xylazine $10 \mathrm{mg} / \mathrm{kg}$ ). Then, the rats were placed in a prone posture on the operating table and the previous sites of treatment were resected. The resected tissues were immediately fixed in formalin and were sent for the pathology report. Based on the defined pathological grading (6-8), the pathology results were classified into 6 groups including: Zero: no change, 1: minor inflammatory infiltration without edema, 2: mild to moderate inflammatory infiltration with mild edema, 3: mild to moderate inflammatory infiltra- tion and moderate edema, 4: moderate inflammation with neutrophils scattered and diffuse edema, 5: severe inflammation of the tissue and edematous changes, fibrosis and hemorrhage.

\subsection{Ethical Considerations}

Animal handling and all experiments were performed in accordance with the international guidelines set out in the Guide for the Care and Use of Laboratory Animals (Institute of Laboratory Animal Resources, 1996) and approved by the local research council at Kashan University of Medical Sciences, Kashan, Iran. (grant number:9378, ethical code:1912)

\subsection{Statistical Analysis}

Data analysis was performed using SPSS software version 16 (SPSS, Inc., Chicago, IL, USA). Kolmogorov-Smirnov test was used to determine if the data are normally distributed and this was not the case. To compare the mean hemostatic time in the aluminum chloride groups, the Kruskal-Wallis test was used. Moreover, the Mann-Whitney $U$ test was used to compare the mean hemostasis times in the aluminum chloride groups and that of the control group (suturing technique).

\section{Results}

\subsection{Hemostatic Results}

The mean hemostatic time in the groups aluminum chloride concentrations of 50\% (Group 5), 25\% (Group 4), 15\% (Group 3), 10\% (Group 2) and 5\% (Group 1) were $8.20 \pm$ $0.919,14.10 \pm 1.37,21.20 \pm 1.31,30.80 \pm 1.68$ and $42.00 \pm 4.19$ seconds, respectively. Also, the mean hemostatic time in the control group (Group 6) was $84.00 \pm 4.05$ seconds (mean \pm standard deviation). A significant difference was observed between the hemostatic time in different concentrations of aluminum chloride (Group 1 and 2, P value $=0.003),($ Group 2 and $3, P$ value $=0.001),($ Group 3 and $4, \mathrm{P}$ value $=0.004),($ Group 4 and $5, P$ value $=0.005)$. Moreover, a significant difference was observed between the hemostatic time in the groups with different concentrations of aluminum chloride and the control group, so that the hemostatic time in all the experimental groups were significantly less than that of the control group ( $P$ value $=0.002)($ Table 1$)$.

\subsection{Pathological Results}

The pathology examination showed that all the wounds were in grade 1 on the third day after the experiment except the wounds in the groups in which $25 \%$ and $50 \%$ concentrations of aluminum chloride were utilized (Table 2). No wound was in grades $0,3,4$ and 5. Acidic property of aluminum chloride can be seen in Figure 1. This acidic property after reaction with blood proteins creates a barrier by coagulated proteins, and prevents the outflow of 
blood from vessels. On the other hand, it prevents the aluminum chloride from entering the vessels, and as a result, it does not allow potential systemic complications of aluminum chloride to appear.

A length of two $\mathrm{cm}$ and a depth of half a cm cut was performed on each rat's shaved back skin by scalpel size NO. 10 (A). Then half a milliliter volume of solution (different concentrations of aluminum chloride) was applied to the incision site by an insulin syringe (B). Acidic property of aluminum chloride after reaction with blood proteins creates a barrier by coagulated proteins, and prevents the outflow of blood from vessels. On the other hand, it prevents the aluminum chloride from entering the vessels, and as a result, it does not allow potential systemic complications of aluminum chloride to appear. Seven days after the treatment, animals were kept at $21 \pm 1^{\circ} \mathrm{C}$ with a 12-hour light/dark cycle (lights on from 8:00 AM to 8:00 PM). They had free access to standard rat chaw and water ad libitum. Afterwards, the rats were anesthetized by intraperitoneal injection of a ketamine/xylazine mixture (ketamine $100 \mathrm{mg} / \mathrm{kg}$ and xylazine $10 \mathrm{mg} / \mathrm{kg}$ ) and the previous sites of treatment were resected for pathological study. Then, rats were killed according to the Guide for the Care and Use of Laboratory Animals (Institute of Laboratory Animal Resources, 1996).

\section{Discussion}

The present study aimed to compare the hemostatic effect of aluminum chloride and simple suturing in controlling external bleeding. The study showed that compared to simple suturing, the hemostasis time was significantly shorter in groups that aluminum chloride

Table 1. The Hemostatic Time Using Different Concentrations of Aluminum Chloride and Suturing Technique in Controlling External Hemorrhage ${ }^{a}$

\begin{tabular}{lcccccc}
\hline Hemostatic Times & $\begin{array}{c}\text { Aluminum } \\
\text { Chloride, 5\% } \\
\text { (Group 1) }\end{array}$ & $\begin{array}{c}\text { Aluminum } \\
\text { Chloride, 10\% } \\
\text { (Group 2) }\end{array}$ & $\begin{array}{c}\text { Aluminum } \\
\text { Chloride, 15\% } \\
\text { (Group 3) }\end{array}$ & $\begin{array}{c}\text { Aluminum } \\
\text { Chloride, 25\% } \\
\text { (Group 4) }\end{array}$ & $\begin{array}{c}\text { Aluminum } \\
\text { Chloride, 50\% } \\
\text { (Group 5) }\end{array}$ & $\begin{array}{c}\text { Suture, } \\
(\text { Group 6) }\end{array}$
\end{tabular}

\begin{tabular}{|c|c|c|c|c|c|c|}
\hline Mean \pm SD $($ second $)$ & $42.00 \pm 4.19$ & $30.80 \pm 1.68$ & $21.20 \pm 1.31$ & $14.10 \pm 1.37$ & $8.20 \pm 0.919$ & $84.00 \pm 4.05$ \\
\hline Median & 41.10 & 32.30 & 20.10 & 12.40 & 7.20 & 80.00 \\
\hline Interquartile range test & 3.40 & 2.70 & 2.40 & 2.30 & 1.80 & 3.90 \\
\hline P Value & 0.002 & & & & & \\
\hline
\end{tabular}

Table 2. The Frequency of Pathological Grade (Grades 0 to 5 Based on the Severity of Pathological Inflammation) Three Days After Exposure to Different Concentrations of Aluminum Chloride and Suturing Technique ${ }^{a}$

\begin{tabular}{|c|c|c|c|c|c|c|}
\hline $\begin{array}{l}\text { Pathological } \\
\text { Grade }\end{array}$ & $\begin{array}{c}\text { Aluminum Chlo- } \\
\text { ride, } 5 \%\end{array}$ & $\begin{array}{c}\text { Aluminum Chlo- } \\
\text { ride, } \mathbf{1 0} \%\end{array}$ & $\begin{array}{c}\text { Aluminum Chlo- } \\
\text { ride, } 15 \%\end{array}$ & $\begin{array}{c}\text { Aluminum Chlo- } \\
\text { ride, } 25 \%\end{array}$ & $\begin{array}{c}\text { Aluminum Chlo- } \\
\text { ride, } \mathbf{5 0} \%\end{array}$ & Suture \\
\hline Grade 1 & $10(100)$ & $10(100)$ & $10(100)$ & $3(30)$ & $1(10)$ & $10(100)$ \\
\hline Grade 2 & 0 & 0 & 0 & $7(70)$ & $9(90)$ & 0 \\
\hline Total & $10(100)$ & $10(100)$ & $10(100)$ & $10(100)$ & $10(100)$ & $10(100)$ \\
\hline
\end{tabular}

a Data are presented as No. (\%)
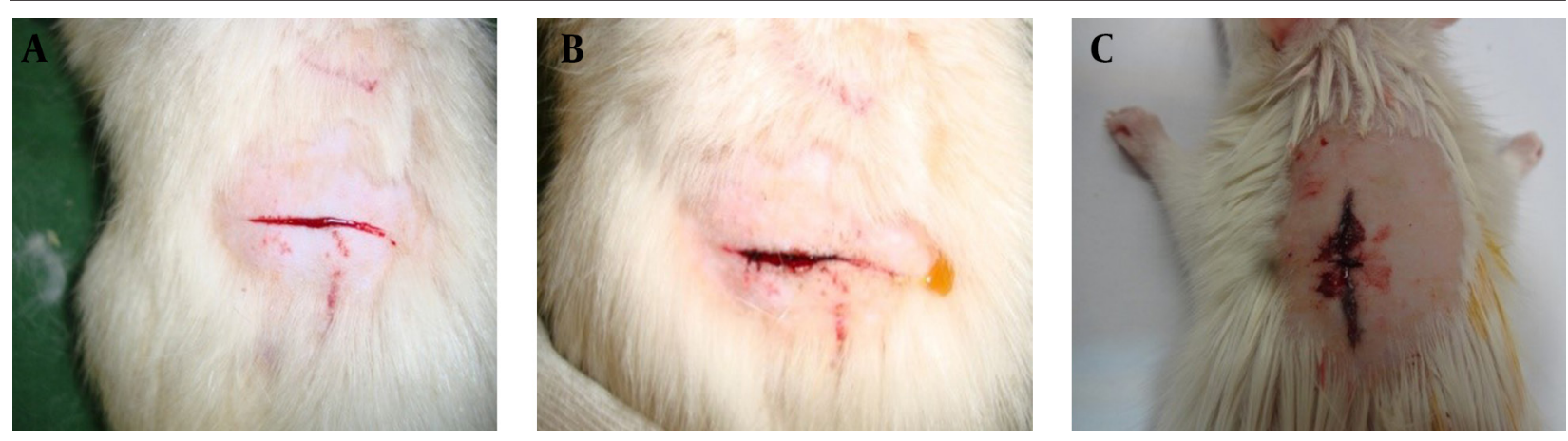

Figure 1. Control of the External Hemorrhage (A) by Aluminum Chloride (50\%) (B) and Suturing Technique (C) 
was used. A number of studies have been conducted on local hemostatic agents and indicate the usefulness of these materials in reducing hemostatic time, and patients' need for blood or blood products, leading to improved prognosis of patients after surgery (9-13).

Most of the local agents currently used to stop external bleeding, stimulate hemostasis on the cut surface and require normal hemostatic systems to exert their functions. Aluminum chloride, unlike the well-known hemostatic agents, exerts its hemostatic effect through a chemical reaction with blood. This property makes it a very efficient hemostatic agent, which does not need normal body hemostatic system to exert its effect. Moreover, the acidic property of aluminum chloride should be considered too. This chemical agent, coagulates the blood proteins and makes a barrier to prevent the outflow of blood from vessels. Such a barrier also blocks the aluminum chloride to enter the vessels and therefore prevents its potential systemic side effects (6). It should be considered that ferric chloride has the same mechanism as aluminum chloride to stop hemorrhage, and it was shown that ferric chloride induces oxidative damage to vascular cells. In fact, ferric chloride is triggering vascular wall injury and denudation of the endothelium via a mechanism involving the generation of reactive oxygen species and induces the amount of micro particles in the circulation after ferric chloride injury (14-16). Others have shown that ferric chloride-injury induces release of endothelial cell derived ferric chloride-filled "buds" that are rich in tissue factor and may contribute to thrombosis (17). Moreover, it was shown that the concentration of ferric chloride is an important component of the injury response in mouse models by influencing the level of endothelial injury and micro particles release after exposing the vessel to oxidative stress (18). Because of this fact, also because we could not find studies, which investigate the hemostatic effect of aluminum chloride in controlling external hemorrhage, we expected lower concentrations of aluminum chloride could not control external hemorrhage. Therefore, different concentrations of aluminum chloride were used in this study. However, the complete hemostasis was occurred in all the groups.

In the current study, we also studied the inflammatory and pathological effect of aluminum chloride on the tissues exposed to it. Pathology reports have shown that the aluminum chloride, even at very high concentrations did not cause inflammation greater than grade two, and immune system reaction to this hemostatic agent does not differ much from the simple sutures. In two studies, Nouri et al. sought the hemostatic effect of ferric sulfate on external bleeding. They have reported that ferric sulfate is an effective hemostatic agent (6). Pathological changes resulted from the ferric sulfate was consistent with the changes occurred in the present study. Nouri et al. noted that the skin tissue of Wistar rat had a slight inflammatory reaction with the ferric sulfate as a foreign body.
According to Kim and Rethnam, a good hemostatic material is the one that stops bleeding in the shortest possible time, one that is easily portable and compatible with life, imposes minimum complication to the patient, does not interfere with tissue healing, with a reasonable price (19). Considering the definition of a hemostatic agent provided by these researchers, the unique features of aluminum chloride, such as not requiring normal hemostatic system for function, make this chemical substance an extremely effective topical hemostatic agent for controlling external bleeding, along with other methods $(20,21)$. Another point should be considered, solution form of aluminum chloride can be used outside the medical centers and by untrained people. Because no study investigates the hemostatic effect of aluminum chloride in controlling external bleeding, we expected lower concentrations of aluminum chloride could not control external bleeding, so we chose higher concentration (50\%) and decreased it to lower concentration (5\%) to find out which concentration can control external bleeding and we have observed that in all the groups complete hemostasis occurred. Due to the financial limitation, using lower concentrations of aluminum chloride was not possible in this study. Authors suggest using the lower concentrations of aluminum chloride in controlling external bleeding in an animal model to determine the lowest concentration of aluminum chloride, which can control external bleeding.

\section{Acknowledgements}

The authors acknowledge with grateful appreciation the kind assistance and financial support provided by the Vice Chancellor for Research at Kashan University of Medical Sciences.

\section{Authors' Contributions}

Saeed Nouri: acquisition of data, snalysis and interpretation of data, study supervision, study concept and design and statistical analysis; Mohammad Reza Sharif: drafting of the manuscript, critical revision of the manuscript for important intellectual content and administrative, technical, and material support; Yunes Panahi: drafting of the manuscript, critical revision of the manuscript for important intellectual content and administrative, technical, and material support; Mostafa Ghanei: drafting of the manuscript, critical revision of the manuscript for important intellectual content; Bardia Jamali: crafting of the manuscript, critical revision of the manuscript for important intellectual content.

\section{Funding/Support}

This study is conducted with financial help and supervision of Vice Chancellor for Research at Kashan University of Medical Sciences. 


\section{References}

1. Champion HR, Bellamy RF, Roberts CP, Leppaniemi A. A profile of combat injury. J Trauma. 2003;54(5 Suppl):S13-9.

2. Kragh JF, Jr., Littrel ML, Jones JA, Walters TJ, Baer DG, Wade CE, et al. Battle casualty survival with emergency tourniquet use to stop limb bleeding. J Emerg Med. 2011;41(6):590-7.

3. Kragh JF, Jr., Murphy C, Dubick MA, Baer DG, Johnson J, Blackbourne LH. New tourniquet device concepts for battlefield hemorrhage control. US Army Med Dep J.2011:38-48.

4. Nouri S, Sharif MR, Tabatabaei F, Farokhi S. Investigating the effect of zinc chloride to control external bleeding in rats. Nurs Midwifery Stud. 2014;3(3).

5. Shen YH, Dempsey BA. Synthesis and speciation of polyaluminum chloride for water treatment. Environ Int.1998;24(8):899-910.

6. Nouri S, Amirbeigy M, Hosseinpour M, Abdorrahim K, Sharif MR. Evaluation of the Hemostatic Effect of Ferric Sulphate in Controlling External Hemorrhage in Rat at Kashan University of Medical Sciences, 2012. Iran J Surg. 2013;21(2):21-9.

7. Nouri S, Sharif MR. Efficacy and safety of ferric chloride in controlling hepatic bleeding; an animal model study. Hepat Mon. $2014 ; 14(6)$.

8. Nouri S, Farokhi S, Jamali B, Sharif MR. Alum in Controlling Hepatic Bleeding; an Animal Model Study. Thrita. 2014;3(3).

9. Berrevoet F, de Hemptinne B. Use of topical hemostatic agents during liver resection. Dig Surg. 2007;24(4):288-93.

10. Nouri S, Sharif MR. Use of Ferric Sulfate to Control Hepatic Bleeding. Trauma Mon. 2015;20(1)

11. Soltani G, Abbasi Tashnizi M, Moeinipour AA, Ganjifard M, Esfahanizadeh J, Sepehri Shamloo A, et al. Comparing the effect of preoperative administration of methylprednisolone and its administration before and during surgery on the clinical out- come in pediatric open heart surgeries. Iran Red Crescent Med J. 2013;15(6):483-7.

12. Nouri S, Sharif MR, Sahba S. The Effect of Ferric Chloride on Superficial Bleeding. Trauma Mon. 2015;20(1).

13. Jackson MR. Fibrin sealants in surgical practice: An overview. Am J Surg. 2001;182(2 Suppl):1S-7S.

14. Ghosh A, Li W, Febbraio M, Espinola RG, McCrae KR, Cockrell E, et al. Platelet CD36 mediates interactions with endothelial cellderived microparticles and contributes to thrombosis in mice. $J$ Clin Invest. 2008;118(5):1934-43.

15. Silverstein RL, Li W, Park YM, Rahaman SO. Mechanisms of cell signaling by the scavenger receptor CD36: implications in atherosclerosis and thrombosis. Trans Am Clin Climatol Assoc. 2010;121:206-20.

16. Li W, Febbraio M, Reddy SP, Yu DY, Yamamoto M, Silverstein RL. CD36 participates in a signaling pathway that regulates ROS formation in murine VSMCs. J Clin Invest. 2010;120(11):3996-4006.

17. Woollard KJ, Sturgeon S, Chin-Dusting JP, Salem HH, Jackson SP. Erythrocyte hemolysis and hemoglobin oxidation promote ferric chloride-induced vascular injury. $J$ Biol Chem. 2009;284(19):13110-8.

18. Harvard School of public health.. The Obesity Prevention Source Obesity Trends. Child Obesity. 2013. Available from: http:/ www.hsph.harvard.edu/obesity-prevention-source/obesitytrends/\%20global\%20-obesity-trends-in-children/.

19. Kim S, Rethnam S. Hemostasis in endodontic microsurgery. Dent Clin North Am. 1997;41(3):499-511.

20. Nouri S, Sharif MR. Hemostatic effect of aluminum chloride in liver bleeding: an animal model study. Tehran Univ Med J. 2014;72(7):435-42.

21. McBee WL, Koerner KR. Review of hemostatic agents used in dentistry. Dent Today. 2005;24(3):62-5 